\title{
Potential Biochemical Mechanisms of Lung Injury in Diabetes
}

\author{
Hong Zheng, ${ }^{1,2}$, Jinzi Wu ${ }^{1}$, Zhen Jin'1, Liang-Jun Yan ${ }^{1, *}$ \\ ${ }^{1}$ Department of Pharmaceutical Sciences, UNT System College of Pharmacy, University of North Texas Health \\ Science Center, Fort Worth, TX 76107, USA \\ ${ }^{2}$ Department of Basic Theory of Traditional Chinese Medicine, College of Basic Medicine, Shandong University \\ of Traditional Chinese Medicine, Jinan, Shandong Province, 250355, China
}

[Received June 9, 2016; Revised June 27, 2016; Accepted June 27, 2016]

\begin{abstract}
Accumulating evidence has shown that the lung is one of the target organs for microangiopathy in patients with either type 1 or type 2 diabetes mellitus (DM). Diabetes is associated with physiological and structural abnormalities in the diabetic lung concurrent with attenuated lung function. Despite intensive investigations in recent years, the pathogenic mechanisms of diabetic lung injury remain largely elusive. In this review, we summarize currently postulated mechanisms of diabetic lung injury. We mainly focus on the pathogenesis of diabetic lung injury that implicates key pathways, including oxidative stress, non-enzymatic protein glycosylation, polyol pathway, NF- $\mathrm{B}$ pathway, and protein kinase $\mathrm{c}$ pathway. We also highlight that while numerous studies have mainly focused on tissue or cell damage in the lung, studies focusing on mitochondrial dysfunction in the diabetic lung have remained sketchy. Hence, further understanding of mitochondrial mechanisms of diabetic lung injury should provide invaluable insights into future therapeutic approaches for diabetic lung injury.
\end{abstract}

Key words: diabetic hyperglycemia, diabetic lung injury, diabetes mellitus, mitochondria, oxidative stress

Diabetes mellitus (DM), characterized by persistent blood hyperglycemia, is a leading cause of morbidity and mortality in the world. A recent report released by the World Health Organization reveals that there were 1.5 million (2.7\%) deaths caused by diabetes in 2012, up from 1.0 million $(2.0 \%)$ in 2000 . The major cause of death in diabetic patients is glucotoxicity-induced complications. There are now increasing evidence showing that lung is also one of the target organs for diabetic microangiopathy in patients with either type 1 or type 2 DM [1-3]. Because the lung microvascular system has huge reserve function, diabetic lung damage is quite subclinical and often ignored by patients and physicians. With continued increase in the occurrence of diabetes in an aging population, more and more pulmonary dysfunction is likely to be attributed to diabetic pulmonary complications. Pulmonary disease associated with diabetes includes a predisposition to infections and chronic obstructive pulmonary disease such as pneumonia, asthma, pulmonary fibrosis, and pulmonary tuberculosis as well as impaired breathing during sleeps [4-11]. Furthermore, it has been reported that incidence death due to pulmonary diseases among Japanese diabetic patients has been found to be greater than 50\% [12]. When compared with healthy subjects, patients with type 1 or type $2 \mathrm{DM}$ are at increased risk for respiratory tract

*Correspondence should be addressed to: Liang-Jun Yan, Ph.D., Department of Pharmaceutical Sciences, UNT System College of Pharmacy, University of North Texas Health Science Center, Fort Worth TX 76107, USA. Email: liang-jun.yan@unthsc.edu

Copyright: () 2017. This is an open-access article distributed under the terms of the Creative Commons Attribution License (CC BY 4.0), which permits unrestricted use, distribution, and reproduction in any medium, provided the original author and source are credited. 
infections and the risk further increases with repeated occurrence of common infections $[13,14]$. Relative risks of developing pulmonary tuberculosis of all types and bacteriologically confirmed cases were 3.47 times and 5.15 times higher, respectively, in diabetic patients than in matched healthy controls [15-18].

Therefore, elucidating the pathogenesis of the diabetic lung injury has become an important research topic. Several concepts of pathogenesis such as oxidative stress, non-enzymatic glycation of proteins, and the polyol pathway have been identified to be involved in the etiology of diabetic lung injury. In this paper, we attempt to provide an overview of the potential and major biochemical mechanisms of morphological changes and pulmonary dysfunction implicated in diabetic lung injury. A deeper understanding of the underlying mechanisms should provide invaluable insights into novel approaches for attenuating diabetic lung injury in the future. It should be noted that this review is by no means to exhaust all the possible mechanisms of diabetic lung injury documented in the literature.

\section{Morphological changes in diabetic lung injury}

Numerous studies indicate physiological and structural abnormalities in diabetic lungs. A histological investigation in rabbit lung shows that diabetic rabbits exhibit morphological abnormalities within 3 weeks of diabetes induction [19]. It has been reported that diabetic hyperglycemia damages the respiratory system due to the pulmonary interstitial injury caused by microangiopathy, which in the meantime could also contribute to autonomic neuropathy [20]. It has also been reported that there is a widely increase in the volume proportion of alveolar wall and alveoli per unit volume, in the relative amounts of collagen, elastin, and basal laminae, and in the surface-tovolume ratio of the lungs of the diabetic rats [21]. The basal membranes were thickened, along with an intense inflammatory reaction in diabetic lungs [22]. The structures of lung tissue and lamellar bodies showed collapse in DM group [23], neutrophil infiltration or aggregation and alveolar wall thickening in lung tissue were significantly higher in the DM group than in the control group [24]. In diabetic lung models, histological examination with Sirius red and eosin and hemotoxylin staining showed fibrosis along with massive inflammatory cell infiltration [25]. The number of tiny villus and the quantity of osmiophilic multilamellar body decreased markedly, while hyperplasia was found in collagen fiber [26]. The mechanisms underlying morphological changes in diabetic lung injury might be the following: (1) Activation of NADPH oxidase that mediates oxidative and nitrosative damage [25]. (2) Activation of the polyol pathway that is one of the most popular candidate mechanisms to explain the cellular toxicity of diabetic hyperglycemia. When glucose concentration in the cell becomes too high, aldose reductase is activated to reduce glucose to sorbitol [27]. Sorbitol can induce cellular osmotic pressure, leading to cell death [28]. On the other hand, as the polyol pathway also consumes NADPH and produces NADH, cellular redox imbalance can occur and trigger oxidative stress, leading to changes in cell membrane integrity and function. (3) Generation of advanced glycation endproducts (AGEs) that can impair protein structure and function.

\section{Pulmonary dysfunction in diabetic lung injury}

Decreased lung function is associated with diabetes, both cross-sectionally and longitudinally [29-33]. It has been found that pulmonary function abnormalities appeared within 3 years of diabetes diagnosis in $51.2 \%$ of children with type 1 diabetes [34] and there is also a statistically significant increase in total airway resistance in children with type 1 diabetes [35]. Airflow restriction is a predictor of demise in type 2 diabetes after adjusting for other recognized risk factors [36]. One study in the Strong Heart Study involving 2,396 adults shows a significantly decreased pulmonary function in American Indians with DM; moreover, lung functional impairment was found to already appear in this ethnic group before the development of overt DM [37] .

\section{Lung ventilatory dysfunction}

Ventilation is an important reflection of lung function. Diabetic patients exhibit a high risk of pulmonary disorders that are often associated with restrictive impairment of lung function. Many cross-sectional studies have consistently shown that when compared with healthy subjects, patients with diabetes have significant decreases in many parameters including lower vital capacity, medium expiratory flow, expiratory residual volume, the total lung capacity (TLC), forced vital capacity (FVC), and forced expiratory volume in one second (FEV1) [38-41]. It has also been reported that the restrictive, but not the obstructive ventilatory dysfunction, is associated with development of prediabetes and precedes the development of type 2 diabetes [42]. Moreover, it has been found that the early stage of diabetes modulates the bronchial reactivity to both acetylcholine and isoproterenol by disrupting the nitric oxide (NO), $\mathrm{K}_{\mathrm{ATP}}$ channels, and cyclooxygenase pathways in guinea pigs [43]. There have been several hypotheses proposed on the mechanism of ventilatory dysfunction in the diabetic lung: (1) Respiratory muscle strength decreased, which was significantly related to 
attenuated lung volumes and ill metabolic control in type 2 diabetes [44-46]. (2) The restrictive type of pulmonary impairment is likely due to non-enzymatic glycosylation of pulmonary proteins and subsequent accumulation of collagen in the lungs and chest wall [30]. Moreover, glycosylation of elastin fibers can also cause improper cross-linking and emphysema-like diminution in alveolar surface area, resulting in stiffening of the lungs, reduced elastic recoil, impaired vascular diffusion, and inflammatory changes in lungs $[47,48]$. (3) Nearly onethird of subjects with diabetes showed abnormal ventilatory response to hypoxia, hypercapnia, or exercise, a symptom of autonomic neuropathy [20]. Moreover, neuroadrenergic bronchopulmonary denervation may also occur in diabetic patients with autonomic neuropathy [49]. Indeed, it has been reported that neuroadrenergic denervation of the lung is associated with the decline of respiratory functional indexes in diabetic patients [50], leading to lung diastolic stress disorder [49]. (4) Nonadrenergic non-cholinergic neurotransmitter release is decreased due to diabetic autonomic neuropathy [51], which could deregulate the pulmonary vascular tone and pulmonary ventilation.

\section{Pulmonary diffusing capacities}

Transfer of oxygen and carbon dioxide over the alveolocapillary membrane is the main function of the lung. Lung diffusing capacity for carbon monoxide (DLCO) is a measure of gas conductance across alveolar tissue membrane into capillary erythrocytes and subsequent chemical binding to hemoglobin. DLCO is influenced by alveolar-capillary membrane conductance and pulmonary capillary blood volume, both of which are reduced in adults with type 1 diabetes [52]. Evidence shows that children with type 1 diabetes also had impaired pulmonary functions including DLCO, airway resistance (Raw), alveolar volume (AV), and_DLCO/AV ratio [53]. It has been demonstrated that there is a significant decrease in the ratio between DLCO and alveolar ventilation in pulmonary gas exchange in the diabetic group when compared with that in healthy controls [54]. DLCO is predominantly due to a low membrane diffusing capacity (DMCO) [55] while in type 2 diabetes both DMCO and capillary blood volume are reduced [38]. Interestingly, at peak exercise, type 1 diabetic subjects demonstrated a decreased DLCO when corrected for cardiac output (DLCO/Q) [56]. Additionally, a decrease in DMCO when corrected for cardiac output (DMCO/Q) was also present and the decrease in diffusing capacity was associated with a reduction in oxygen saturation. It is suggested that the limitation in gas transfer becomes functionally important as the transit time of red blood cells through the lung is shortened [56].

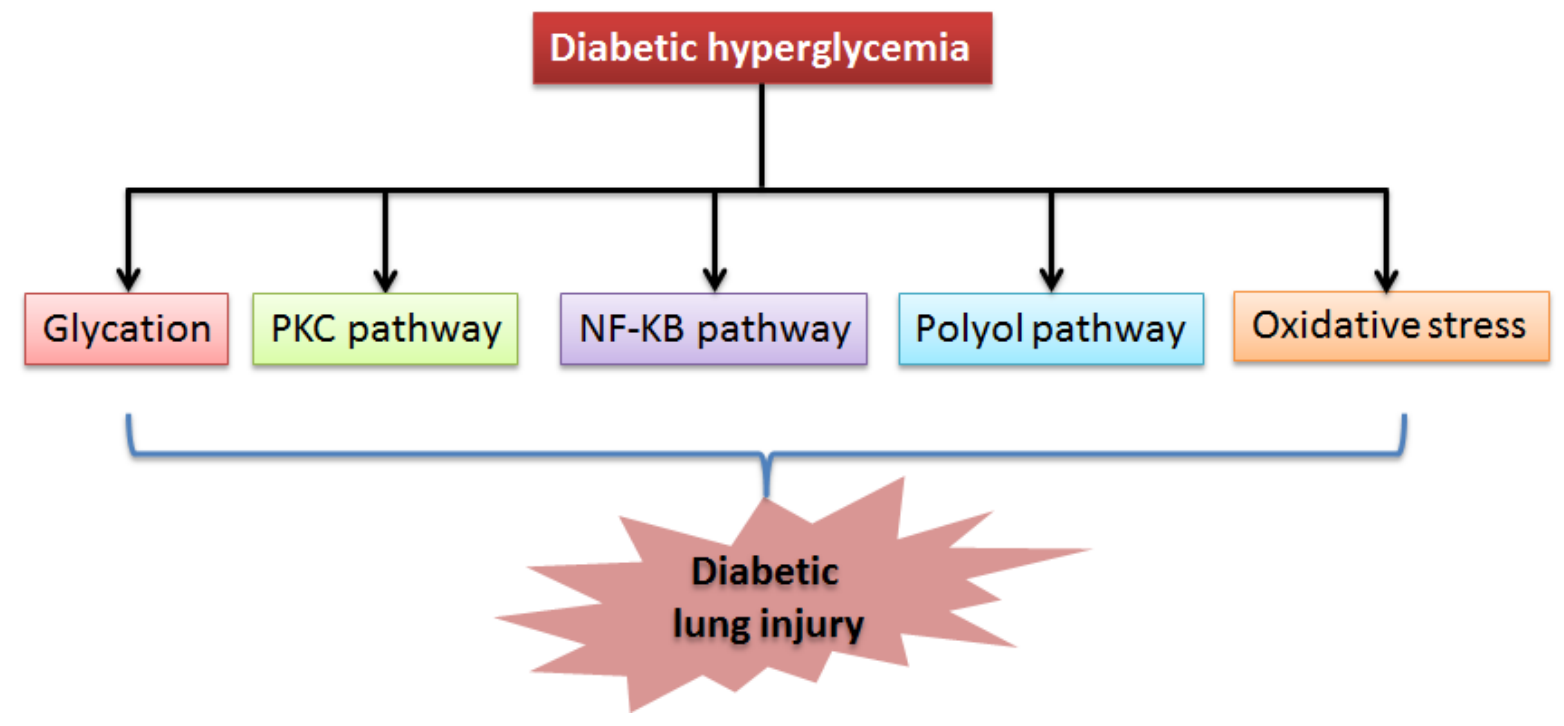

Figure 1. Hyperglycemia-upregulated pathways that are potentially involved in diabetic lung injury. These include protein glycation, PKC pathway, NF-KB pathway, polyol pathway, and oxidative stress. It should be noted that these pathways may be inter-related. For example, the polyol pathway can also contribute to oxidative stress. 


\section{Etiopathogenesis of diabetic lung injury}

There is increasingly a large body of supporting data that may provide mechanisms of pathogenesis of diabetic lung injury. However, a detailed elucidation of each mechanism remains challenging. Long lasting hyperglycemia triggers upregulation of a variety of pathways, including oxidative stress, non-enzymatic glycation of proteins, polyol pathway and sorbitol production, NF- $\mathrm{kB}$ pathway, and activation of the protein kinase $\mathrm{C}$ pathway (Fig. 1). Here we review these mainstream mechanisms that have been implicated in diabetic lung injury.

\section{Oxidative stress}

Previous experimental and clinical studies indicate that hyperglycemia-induced overproduction of superoxide plays a key role in the pathogenesis and development of diabetic complications in all kinds of tissue injuries [5759]. Sustained hyperglycemia produces excessive reactive oxygen species (ROS) and reactive nitrogen species (RNS) that cannot be overwhelmed by antioxidants, resulting in damage to DNA, lipids, and proteins [60-63]. Evidence indicates that in diabetic lung, the activity of superoxide dismutase (SOD) was decreased, while the contents of nitric oxide (NO) and malondialdehyde (MDA) were significantly increased [23, 26]. As NO and superoxide can react simultaneously to produce peroxynitrite that is very damaging [64], any evidence that $\mathrm{NO}$ concentration is elevated in the diabetic lung would suggest that $\mathrm{NO}$ /peroxynitrite pathway is a mechanism by which lung is injured. The pulmonary lipid peroxidation, glutathione peroxidase activities and inducible nitric oxide synthase (iNOS) were all found to be increased in streptozotocin diabetic rats [65]. Immunohistochemical staining in the pulmonary bronchial epithelium and capillary endothelium in the DM group indicates an elevated level of iNOS expression [65]. It has also been shown that $8-\mathrm{OHdG}$ increases in patients with type 2 diabetes [66], demonstrating the occurrence of DNA damage in the diabetic lungs. Clinic data illustrates that tumor necrosis factor-alpha (TNF- a), interleukin-6 (IL-6), interleukin-10 (IL-10), and MDA levels in serum were all significantly increased in diabetic patients who show diabetic lung injury [67]. Additionally, it has been reported that in type 2 diabetes patients with pneumonia, levels of toll-like receptor $2 / 4$ in peripheral blood monocytes and serum surfactant protein A were altered [68]. All these studies demonstrate the involvement of oxidative damage in diabetic lung injury.

\section{Non-enzymatic protein glycosylation}

Nonenzymatic glycosylation is accelerated by oxidative stress and elevated levels of aldoses [69]. AGEs are a heterogeneous group of modified proteins, lipids and nucleic acids arising from intracellular hyperglycemia via a non-enzymatic Maillard reaction [63]. This modification can result in changes in tissue/cellular properties by forming crosslinks [70] that impair the biological functions of the target proteins [71]. Tissues exposed to continuous state of high blood glucose can exhibit non-enzymatic glycosylation of proteins, whereby AGEs are eventually formed [72]. It has been suggested that formation and accumulation of AGEs are involved in the pathogenesis of diabetic vascular complications [73]. As reactive oxygen intermediates are involved in the formation of AGE structures such as carboxymethyllysine [74], the interaction of AGE modified proteins with macrophages might further induce macrophage ROS production, thereby contributing to the development of pulmonary fibrosis [75].

Therefore, hyperglycemia-accelerated formation of nonenzymatic advanced glycosylation end products in tissues has been suggested as the central pathologic features of diabetic complications [76]. Interaction of AGEs with the receptor for advanced glycation endproducts (RAGE) has been shown to activate downstream signaling pathways and evoke inflammatory responses in vascular wall cells [77, 78]. Glycation can upregulate transforming growth factor- $\beta$ intermediate and lead to increased synthesis of collagen, laminin, and fibronectin in the extracellular matrix $[79,80]$.

\section{Polyol pathway}

Polyol pathway is one of the major sources of ROS production in diabetes [81]. Hyperglycemia decreases $\mathrm{NAD}^{+}$levels by activation of the polyol pathway and by over-activation of poly (ADP-ribose)-polymerase (PARP) [82]. The pulmonary arteries from diabetic rats showed impaired relaxant response to acetylcholine and decreased vasoconstrictor response to N-omega-nitro-L-arginine methyl ester (L-NAME) that is a widely used NOS inhibitor. It has also been suggested that diabetes induces pulmonary artery endothelial dysfunction by enhancing superoxide production [83]. In experimental diabetic lung in rabbits, it was found that glutathione peroxidase (GSHPx) activity, glutathione reductase (GSSG-R) activity, and ascorbic acid level decreased while the concentration of lipid peroxidation products increased [84]. Therefore, it is conceivable that the lowered level of $\mathrm{NAD}^{+}$in the diabetic lung may aggravate cellular and tissue damage. The levels of free $15-\mathrm{F}_{2 t}$-isoprostane were increased in lung tissues in diabetic rats along with a significantly 
increased membrane translocation of the NADPH oxidase subunit p67phox and increased expression of the membrane-bound subunit p22phox in diabetic lung [85]. Additionally, damaged mitochondria can also generate an excess of superoxide that can mediate tissue injury in diabetes. Studies conducted in diabetic rats have revealed significant generation of mitochondrial superoxide at the site of NADH/ubiquinone oxidoreductase (complex I) [86, 87].

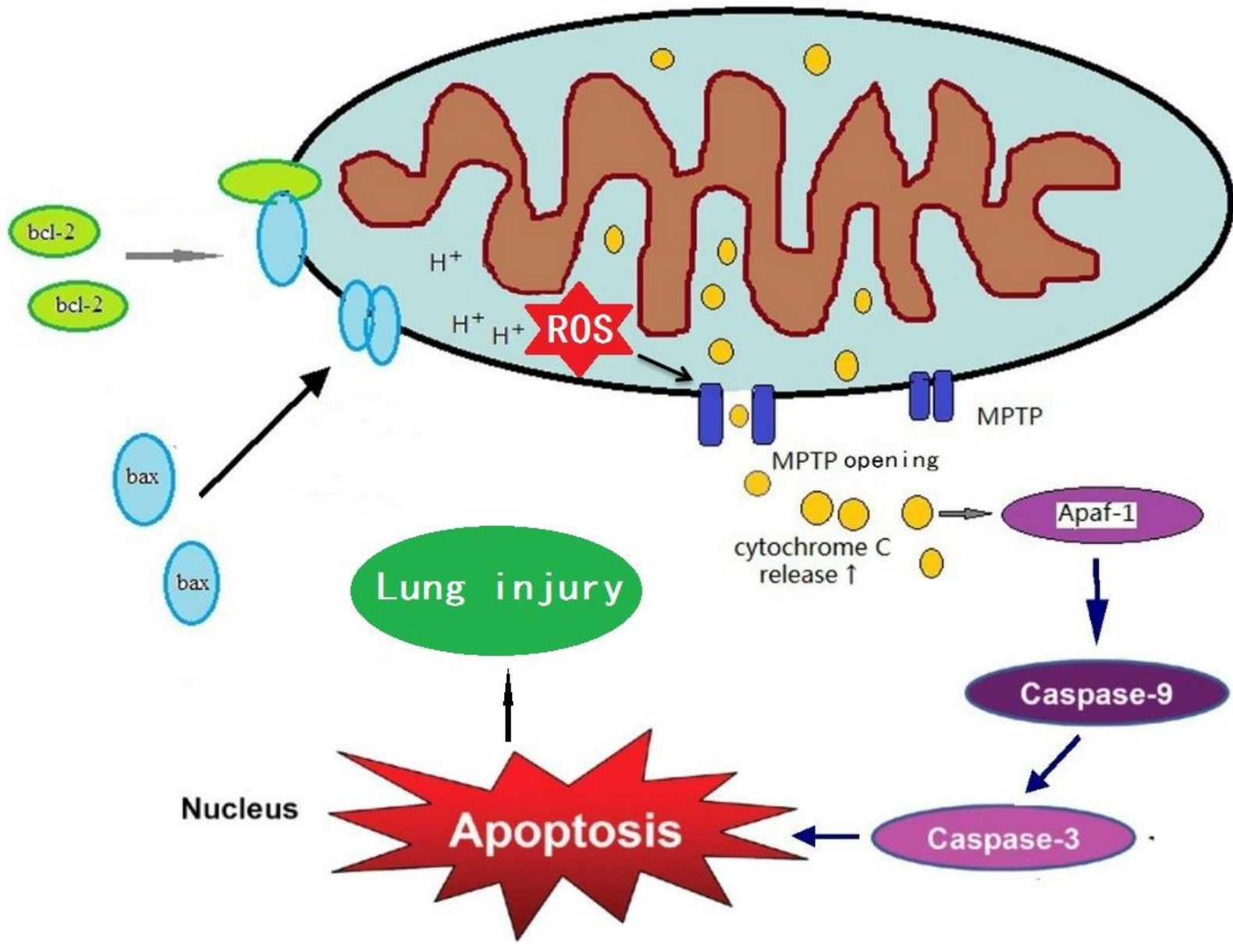

Figure 2. Possible role of mitochondrial dysfunction in diabetic lung injury. Show is the mitochondrial elements that are involved in cell death. Initial production of mitochondrial ROS can lead to changes in membrane potential and opening of mitochondrial permeability transition pore (MPTP) opening. MPTP opening could further enhance mitochondrial ROS production, forming a vicious cycle that eventually leads to cell death and lung dysfunction.

\section{$N F-\kappa B$ pathway}

The nuclear factor (NF) $-\kappa \mathrm{B}$ signaling pathway is involved in regulating gene expression in early inflammatory responses. NF- $\mathrm{KB}$ pathway is a primary target for activation by hyperglycemia, oxidative stress, and inflammatory cytokines [88]. The expression of TNF- $\alpha$, IL-1 $\beta$, IL-6 and other pro-inflammatory cytokines are regulated downstream of NF- $\kappa \mathrm{B}$ [89]. NF- $\kappa \mathrm{B}$ has been shown to activate the genes encoding pro-inflammatory cytokines, cell adhesion molecules, nitric oxide synthase, and cyclooxygenase-2 [90]. In the lung tissues of diabetic rats, it has been reported that while the levels of I $\mathrm{I} B$ were declined when compared with that in the control group, the levels of phosphorylated $\mathrm{I} \kappa \mathrm{B}$ and nuclear NF- $\kappa \mathrm{B}$ were actually elevated. Meanwhile, the mRNA levels and protein levels of iNOS and cyclooxygenase-2 were also up-regulated in the lung tissue of diabetic animals [91]. Additionally, protein carbonyl content was higher in diabetic lungs, but SOD and GSH activities were lower 
[22]. Hence, it seems that lungs are exposed to oxidative stress mediated by NF- $\kappa$ B activation in diabetes.

\section{Protein Kinase C pathways}

Protein kinase $\mathrm{C}(\mathrm{PKC})$ is a family of enzymes that are involved in regulating the function of numerous proteins. $\mathrm{PKC}$ has been associated with vascular alterations such as increase in permeability, contractility, extracellular matrix synthesis, cell growth and apoptosis, angiogenesis, leukocyte adhesion, and cytokine activation and inhibition. It has been demonstrated that diabetic rats exhibited a significant decrease in LPS-induced phosphorylation of extracellular signal-regulated kinase, protein kinase $\mathrm{C} \alpha$ and $\delta, \mathrm{p} 38$, and protein kinase $\mathrm{B}$ [92]. Additionally, expression of iNOS and levels of IL-6 and cyclooxygenase are also decreased in the lung homogenates derived from diabetic rats [92]. In particular, PKC activation by hyperglycemia can activate NADPH oxidase that generates more ROS and accentuates oxidative stress [93]. Therefore, PKC dysregulation could be involved in diabetic lung injury.

\section{Role of mitochondrial dysfunction in diabetic lung injury}

Mitochondria are important organelles for cell survival [94, 95]. Mitochondria play important roles in intracellular energy generation, in modulation of apoptosis, and in redox-dependent intracellular signaling [96]. Mitochondria can be both a source of ROS and a target of oxidative damage during oxidative stress. Hence, numerous studies attempting to link mitochondria to the complications of diabetes has focused on the role of mitochondrial ROS [97-100]. Prolonged hyperglycemia results in an over-generation of ROS by the mitochondria, which in turn may contribute significantly to the development of diabetic complications [100]. Interestingly, AMP kinase (AMPK) seems to be involved in the pathogenesis of diabetic complications. It has been reported in diabetes that C-peptide induces AMPK $\alpha$ activation and inhibits hyperglycemia-induced ROS production, mitochondrial membrane potential collapse, mitochondrial fission, and endothelial cell apoptosis [101]. It has also been demonstrated that increased mitochondrial ROS in diabetes is maintained by a feedforward AMPK activation cascade [102]. Interestingly, basal ROS concentration was increased in lymphocytes from type $2 \mathrm{DM}$ and triiodothyronine $\left(\mathrm{T}_{3}\right)$ significantly stimulated ROS concentration in type $2 \mathrm{DM}$ patients. Thus an increased mitochondrial sensitivity for $\mathrm{T}_{3}$ may be a significant factor responsible for increased ROS production in diabetic patients [103].
Moreover, hyperglycemia-induced over-production of mitochondrial ROS may lead to collapse of mitochondrial transmembrane potential and opening of the mitochondrial permeability transition pore (MPTP) $[100,104,105]$. The occurrence of apoptosis via cytochrome $\mathrm{c}$ release induced by MPTP opening may lead to more ROS generation [106, 107], forming a vicious cycle that eventually results in cell death [108] (Fig. 2). Conversely, therapeutic inhibition of mitochondrial ROS by antioxidants such as mito-TEMPO can decrease adverse cellular changes and mitigate cellular dysfunction in diabetic mice [109]. Thus, antioxidants targeting mitochondria could be an effective therapeutic approach for diabetic complications in the lung [110].

Based on research in other diabetic organs or tissues, we envision that defective or insufficient mitochondrial function plays potentially a pathogenic role in diabetic lung injury. Therefore, qualitative and quantitative analysis on functional perturbations of mitochondria needs to be conducted in the diabetic lung. In particular, the state of both mitochondrial transmembrane potential and the opening of MPTP in the diabetic lung injury need to be assessed.

\section{Summary}

While numerous studies have shown that the lung is one of the target organs of diabetes, the biochemical pathogenesis of diabetic lung injury remains largely unexplored. In this review, we have summarized experimental and clinical evidence demonstrating diabetic lung dysfunction manifested by morphological and pathological changes. As sustained hyperglycemia could result in oxidative stress which contributes to tissue damage, oxidative stress has been postulated to be a major contributing factor in diabetic lung injury. Nonetheless, the role of mitochondria, a major source of ROS and oxidative stress, in diabetic lung injury has yet to be fully explored. Therefore, more studies should focus on mitochondrial dysfunction in the diabetic lung in the future, which will offer invaluable insights into design of therapeutic approaches for diabetic lung injury.

\section{Conflict of interest}

\section{None}

\section{References}

[1] Pitocco D, Fuso L, Conte EG, Zaccardi F, Condoluci C, Scavone G, et al. (2012). The diabetic lung--a new target organ? Rev Diabet Stud, 9 (1): 23-35. Kuitert LM (2008). The lung in diabetes--yet another target organ? Chron Respir Dis, 5 (2): 67-68. 
[3] Sandler M (1990). Is the lung a 'target organ' in diabetes mellitus? Arch Intern Med, 150 (7): 13851388.

[4] Hsiao YT, Cheng WC, Liao WC, Lin CL, Shen TC, Chen WC, et al. (2015). Type 1 Diabetes and Increased Risk of Subsequent Asthma: A Nationwide Population-Based Cohort Study. Medicine (Baltimore), 94 (36): e1466.

[5] Black MH, Anderson A, Bell RA, Dabelea D, Pihoker C, Saydah S, et al. (2011). Prevalence of asthma and its association with glycemic control among youth with diabetes. Pediatrics, 128 (4): e839-847.

[6] Carlsson AC, Wandell P, Osby U, Zarrinkoub R, Wettermark B, Ljunggren G (2013). High prevalence of diagnosis of diabetes, depression, anxiety, hypertension, asthma and COPD in the total population of Stockholm, Sweden - a challenge for public health. BMC Public Health, 13: 670.

[7] d'Annunzio G, Tosca MA, Pistorio A, Silvestri M, Romanisio G, Lorini R, et al. (2015). Type 1 diabetes mellitus and asthma: A follow-up study. Allergol Immunopathol (Madr), 43 (2): 225-227.

[8] Kent BD, Grote L, Ryan S, Pepin JL, Bonsignore MR, Tkacova R, et al. (2014). Diabetes mellitus prevalence and control in sleep-disordered breathing: the European Sleep Apnea Cohort (ESADA) study. Chest, 146 (4): 982-990.

[9] Wu Z, Guo J, Huang Y, Cai E, Zhang X, Pan Q, et al. (2016). Diabetes mellitus in patients with pulmonary tuberculosis in an aging population in Shanghai, China: Prevalence, clinical characteristics and outcomes. J Diabetes Complications, 30 (2): 237-241.

[10] Ehrlich SF, Quesenberry CP, Jr., Van Den Eeden SK, Shan J, Ferrara A (2010). Patients diagnosed with diabetes are at increased risk for asthma, chronic obstructive pulmonary disease, pulmonary fibrosis, and pneumonia but not lung cancer. Diabetes Care, 33 (1): 55-60.

[11] Hu Y, Ma Z, Guo Z, Zhao F, Wang Y, Cai L, et al. (2014). Type 1 diabetes mellitus is an independent risk factor for pulmonary fibrosis. Cell Biochem Biophys, 70 (2): 1385-1391.

[12] Goto Y, Sato SI, Masuda M (1974). Causes of death in 3151 diabetic autopsy cases. Tohoku J Exp Med, 112 (4): 339-353.

[13] Klekotka RB, Mizgala E, Krol W (2015). The etiology of lower respiratory tract infections in people with diabetes. Pneumonol Alergol Pol, 83 (5): 401-408.

[14] Muller LM, Gorter KJ, Hak E, Goudzwaard WL, Schellevis FG, Hoepelman AI, et al. (2005). Increased risk of common infections in patients with type 1 and type 2 diabetes mellitus. Clin Infect Dis, 41 (3): 281288.

[15] Silwer H, Oscarsson PN (1958). Incidence and coincidence of diabetes mellitus and pulmonary tuberculosis in a Swedish county. Acta Med Scand Suppl, 335: 1-48.

[16] Thanh NP, Khue PM, Sy DN, Strobel M (2015). [Diabetes among new cases of pulmonary tuberculosis in Hanoi, Vietnam]. Bull Soc Pathol Exot.
[17] Balakrishnan S, Vijayan S, Nair S, Subramoniapillai J, Mrithyunjayan S, Wilson N, et al. (2012). High diabetes prevalence among tuberculosis cases in Kerala, India. PLoS One, 7 (10): e46502.

[18] Kim SJ, Hong YP, Lew WJ, Yang SC, Lee EG (1995). Incidence of pulmonary tuberculosis among diabetics. Tuber Lung Dis, 76 (6): 529-533.

[19] McCloud LL, Parkerson JB, Zou L, Rao RN, Catravas JD (2004). Reduced pulmonary endothelium-bound angiotensin converting enzyme activity in diabetic rabbits. Vascul Pharmacol, 41 (4-5): 159-165.

[20] Williams JG, Morris AI, Hayter RC, Ogilvie CM (1984). Respiratory responses of diabetics to hypoxia, hypercapnia, and exercise. Thorax, 39 (7): 529-534.

[21] Kida K, Utsuyama M, Takizawa T, Thurlbeck WM (1983). Changes in lung morphologic features and elasticity caused by streptozotocin-induced diabetes mellitus in growing rats. Am Rev Respir Dis, 128 (1): 125-131.

[22] Eren G, Cukurova Z, Hergunsel O, Demir G, Kucur M, Uslu E, et al. (2010). Protective effect of the nuclear factor kappa B inhibitor pyrrolidine dithiocarbamate in lung injury in rats with streptozotocin-induced diabetes. Respiration, 79 (5): 402-410.

[23] Hu JF, Zhang GJ, Wang L, Kang PF, Li J, Wang HJ, et al. (2014). Ethanol at low concentration attenuates diabetes induced lung injury in rats model. J Diabetes Res, 2014: 107152.

[24] Alkan M, Celik A, Bilge M, Kiraz HA, Kip G, Ozer A, et al. (2015). The effect of levosimendan on lung damage after myocardial ischemia reperfusion in rats in which experimental diabetes was induced. J Surg Res, 193 (2): 920-925.

[25] Yang J, Tan Y, Zhao F, Ma Z, Wang Y, Zheng S, et al. (2011). Angiotensin II plays a critical role in diabetic pulmonary fibrosis most likely via activation of NADPH oxidase-mediated nitrosative damage. Am J Physiol Endocrinol Metab, 301 (1): E132-144.

[26] Liang JQ, Ding CH, Ling YL, Xu HB, Lu P, Xian XH (2007). [The protective function of puerarin to the injury of the lung and its mechanisms during diabetes]. Zhongguo Ying Yong Sheng Li Xue Za Zhi, 23 (3): 355-358.

[27] Luo X, Wu J, Jing S, Yan LJ (2016). Hyperglycemic Stress and Carbon Stress in Diabetic Glucotoxicity. Aging Dis, 7 (1): 90-110.

[28] Wu J, Jin Z, Zheng H, Yan LJ (2016). Sources and implications of $\mathrm{NADH} / \mathrm{NAD}+$ redox imbalance in diabetes and its complications. Diabetes Metab Syndr Obes, 9: 145-153.

[29] Teeter JG, Riese RJ (2008). Cross-sectional and prospective study of lung function in adults with type 2 diabetes: the Atherosclerosis Risk in Communities (ARIC) study: response to Yeh et al. Diabetes Care, 31 (10): e82.

[30] Yeh HC, Punjabi NM, Wang NY, Pankow JS, Duncan BB, Cox CE, et al. (2008). Cross-sectional and prospective study of lung function in adults with type 2 diabetes: the Atherosclerosis Risk in Communities (ARIC) study. Diabetes Care, 31 (4): 741-746. 
[31] Dennis RJ, Maldonado D, Rojas MX, Aschner P, Rondon M, Charry L, et al. (2010). Inadequate glucose control in type 2 diabetes is associated with impaired lung function and systemic inflammation: a crosssectional study. BMC Pulm Med, 10: 38.

[32] Lange P, Groth S, Kastrup J, Mortensen J, Appleyard M, Nyboe J, et al. (1989). Diabetes mellitus, plasma glucose and lung function in a cross-sectional population study. Eur Respir J, 2 (1): 14-19.

[33] Engstrom G, Hedblad B, Nilsson P, Wollmer P, Berglund G, Janzon L (2003). Lung function, insulin resistance and incidence of cardiovascular disease: a longitudinal cohort study. J Intern Med, 253 (5): 574581.

[34] Suresh V, Reddy A, Mohan A, Rajgopal G, Satish P, Harinarayan C, et al. (2011). High prevalence of spirometric abnormalities in patients with type 1 diabetes mellitus. Pediatr Endocrinol Diabetes Metab, 17 (2): 71-75.

[35] van Gent R, Brackel HJ, de Vroede M, van der Ent CK (2002). Lung function abnormalities in children with type I diabetes. Respir Med, 96 (12): 976-978.

[36] Davis WA, Knuiman M, Kendall P, Grange V, Davis TM, Fremantle Diabetes S (2004). Glycemic exposure is associated with reduced pulmonary function in type 2 diabetes: the Fremantle Diabetes Study. Diabetes Care, 27 (3): 752-757.

[37] Yeh F, Dixon AE, Marion S, Schaefer C, Zhang Y, Best LG, et al. (2011). Obesity in adults is associated with reduced lung function in metabolic syndrome and diabetes: the Strong Heart Study. Diabetes Care, 34 (10): 2306-2313.

[38] Fontaine-Delaruelle C, Viart-Ferber C, Luyton C, Couraud S (2016). [Lung function in patients with diabetes mellitus]. Rev Pneumol Clin, 72 (1): 10-16.

[39] Aparna (2013). Pulmonary function tests in type 2 diabetics and non-diabetic people -a comparative study. J Clin Diagn Res, 7 (8): 1606-1608.

[40] Dharwadkar AR, Dharwadkar AA, Banu G, Bagali S (2011). Reduction in lung functions in type-2 diabetes in Indian population: correlation with glycemic status. Indian J Physiol Pharmacol, 55 (2): 170-175.

[41] Huang H, Guo Q, Li L, Lin S, Lin Y, Gong X, et al. (2014). Effect of type 2 diabetes mellitus on pulmonary function. Exp Clin Endocrinol Diabetes, 122 (6): 322-326.

[42] Kim CH, Kim HK, Kim EH, Bae SJ, Jung YJ, Choi J, et al. (2015). Association of restrictive ventilatory dysfunction with the development of prediabetes and type 2 diabetes in Koreans. Acta Diabetol, 52 (2): $357-$ 363.

[43] Saidullah B, Muralidhar K, Fahim M (2014). Onset of diabetes modulates the airway smooth muscle reactivity of guinea pigs: role of epithelial mediators. J Smooth Muscle Res, 50: 29-38.

[44] Fuso L, Pitocco D, Longobardi A, Zaccardi F, Contu C, Pozzuto C, et al. (2012). Reduced respiratory muscle strength and endurance in type 2 diabetes mellitus. Diabetes Metab Res Rev, 28 (4): 370-375.

[45] Nakajima K, Kubouchi Y, Muneyuki T, Ebata M,
Eguchi S, Munakata H (2008). A possible association between suspected restrictive pattern as assessed by ordinary pulmonary function test and the metabolic syndrome. Chest, 134 (4): 712-718.

[46] Litonjua AA, Lazarus R, Sparrow D, Demolles D, Weiss ST (2005). Lung function in type 2 diabetes: the Normative Aging Study. Respir Med, 99 (12): 15831590.

[47] Sternberg M, Cohen-Forterre L, Peyroux J (1985). Connective tissue in diabetes mellitus: biochemical alterations of the intercellular matrix with special reference to proteoglycans, collagens and basement membranes. Diabete Metab, 11 (1): 27-50.

[48] Hamlin CR, Kohn RR, Luschin JH (1975). Apparent accelerated aging of human collagen in diabetes mellitus. Diabetes, 24 (10): 902-904.

[49] Antonelli Incalzi R, Fuso L, Giordano A, Pitocco D, Maiolo C, Calcagni ML, et al. (2002). Neuroadrenergic denervation of the lung in type I diabetes mellitus complicated by autonomic neuropathy. Chest, 121 (2): 443-451.

[50] Antonelli Incalzi R, Fuso L, Pitocco D, Basso S, Trove A, Longobardi A, et al. (2007). Decline of neuroadrenergic bronchial innervation and respiratory function in type 1 diabetes mellitus: a longitudinal study. Diabetes Metab Res Rev, 23 (4): 311-316.

[51] Jenkinson KM, Reid JJ (2000). Altered non-adrenergic non-cholinergic neurotransmission in gastric fundus from streptozotocin-diabetic rats. Eur J Pharmacol, 401 (2): 251-258.

[52] Lee MJ, Coast JR, Hempleman SC, Baldi JC (2016). Type 1 Diabetes Duration Decreases Pulmonary Diffusing Capacity during Exercise. Respiration, 91 (2): 164-170.

[53] Martin-Frias M, Lamas A, Lara E, Alonso M, Ros P, Barrio R (2015). Pulmonary function in children with type 1 diabetes mellitus. J Pediatr Endocrinol Metab, 28 (1-2): 163-169.

[54] Guvener N, Tutuncu NB, Akcay S, Eyuboglu F, Gokcel A (2003). Alveolar gas exchange in patients with type 2 diabetes mellitus. Endocr J, 50 (6): 663667.

[55] Shah SH, Sonawane P, Nahar P, Vaidya S, Salvi S (2013). Pulmonary function tests in type 2 diabetes mellitus and their association with glycemic control and duration of the disease. Lung India, 30 (2): 108112.

[56] Wheatley CM, Baldi JC, Cassuto NA, Foxx-Lupo WT, Snyder EM (2011). Glycemic control influences lung membrane diffusion and oxygen saturation in exercise-trained subjects with type 1 diabetes: alveolar-capillary membrane conductance in type 1 diabetes. Eur J Appl Physiol, 111 (3): 567-578.

[57] Brownlee M (2001). Biochemistry and molecular cell biology of diabetic complications. Nature, 414 (6865): 813-820.

[58] Folli F, Corradi D, Fanti P, Davalli A, Paez A, Giaccari A, et al. (2011). The role of oxidative stress in the pathogenesis of type 2 diabetes mellitus micro- and macrovascular complications: avenues for a 
mechanistic-based therapeutic approach. Curr Diabetes Rev, 7 (5): 313-324.

[59] Lapolla A, Fedele D (1993). [Oxidative stress and diabetes: role in the development of chronic complications]. Minerva Endocrinol, 18 (3): 99-108.

[60] Redmann M, Darley-Usmar V, Zhang J (2016). The Role of Autophagy, Mitophagy and Lysosomal Functions in Modulating Bioenergetics and Survival in the Context of Redox and Proteotoxic Damage: Implications for Neurodegenerative Diseases. Aging Dis, 7 (2): 150-162.

[61] Yan LJ (2014). Positive oxidative stress in aging and aging-related disease tolerance. Redox Biol, 2C: 165169.

[62] Yan LJ (2014). Protein redox modification as a cellular defense mechanism against tissue ischemic injury. Oxid Med Cell Longev, 2014: 343154.

[63] Zheng H, Wu J, Jin Z, Yan LJ (2016). Protein Modifications as Manifestations of Hyperglycemic Glucotoxicity in Diabetes and Its Complications. Biochem Insights, 9: 1-9.

[64] Radi R (1998). Peroxynitrite reactions and diffusion in biology. Chem Res Toxicol, 11 (7): 720-721.

[65] Di Naso FC, de Mello RN, Bona S, Dias AS, Porawski M, Ferraz Ade B, et al. (2010). Effect of Agaricus blazei Murill on the pulmonary tissue of animals with streptozotocin-induced diabetes. Exp Diabetes Res, 2010: 543926.

[66] Nishikawa T, Sasahara T, Kiritoshi S, Sonoda K, Senokuchi T, Matsuo T, et al. (2003). Evaluation of urinary 8-hydroxydeoxy-guanosine as a novel biomarker of macrovascular complications in type 2 diabetes. Diabetes Care, 26 (5): 1507-1512.

[67] Xiong XQ, Wang WT, Wang LR, Jin LD, Lin LN (2012). Diabetes increases inflammation and lung injury associated with protective ventilation strategy in mice. Int Immunopharmacol, 13 (3): 280-283.

[68] Que Y, Shen X (2016). Changes in blood monocyte Toll-like receptor and serum surfactant protein A reveal a pathophysiological mechanism for community-acquired pneumonia in patients with type 2 diabetes. Intern Med J, 46 (2): 213-219.

[69] Baynes JW, Thorpe SR (1999). Role of oxidative stress in diabetic complications: a new perspective on an old paradigm. Diabetes, 48 (1): 1-9.

[70] Brownlee M, Vlassara H, Kooney A, Ulrich P, Cerami A (1986). Aminoguanidine prevents diabetes-induced arterial wall protein cross-linking. Science, 232 (4758): 1629-1632.

[71] Hammes HP, Weiss A, Hess S, Araki N, Horiuchi S, Brownlee M, et al. (1996). Modification of vitronectin by advanced glycation alters functional properties in vitro and in the diabetic retina. Lab Invest, 75 (3): 325338.

[72] Vlassara H, Bucala R, Striker L (1994). Pathogenic effects of advanced glycosylation: biochemical, biologic, and clinical implications for diabetes and aging. Lab Invest, 70 (2): 138-151.

[73] Chilelli NC, Burlina S, Lapolla A (2013). AGEs, rather than hyperglycemia, are responsible for microvascular complications in diabetes: a "glycoxidation-centric" point of view. Nutr Metab Cardiovasc Dis, 23 (10): 913-919.

[74] Nagai R, Ikeda K, Higashi T, Sano H, Jinnouchi Y, Araki T, et al. (1997). Hydroxyl radical mediates $N$ epsilon-(carboxymethyl)lysine formation from Amadori product. Biochem Biophys Res Commun, 234 (1): 167-172.

[75] Matsuse T, Ohga E, Teramoto S, Fukayama M, Nagai $\mathrm{R}$, Horiuchi S, et al. (1998). Immunohistochemical localisation of advanced glycation end products in pulmonary fibrosis. J Clin Pathol, 51 (7): 515-519.

[76] Brownlee M, Cerami A, Vlassara H (1988). Advanced glycosylation end products in tissue and the biochemical basis of diabetic complications. N Engl J Med, 318 (20): 1315-1321.

[77] Yamagishi S, Nakamura K, Matsui T (2006). Advanced glycation end products (AGEs) and their receptor (RAGE) system in diabetic retinopathy. Curr Drug Discov Technol, 3 (1): 83-88.

[78] Zong H, Ward M, Stitt AW (2011). AGEs, RAGE, and diabetic retinopathy. Curr Diab Rep, 11 (4): 244-252.

[79] Goldin A, Beckman JA, Schmidt AM, Creager MA (2006). Advanced glycation end products: sparking the development of diabetic vascular injury. Circulation, 114 (6): 597-605.

[80] Throckmorton DC, Brogden AP, Min B, Rasmussen H, Kashgarian M (1995). PDGF and TGF-beta mediate collagen production by mesangial cells exposed to advanced glycosylation end products. Kidney Int, 48 (1): 111-117.

[81] Yan LJ (2014). Pathogenesis of chronic hyperglycemia: from reductive stress to oxidative stress. J Diabetes Res, 2014: 137919.

[82] Boesten DM, von Ungern-Sternberg SN, den Hartog GJ, Bast A (2015). Protective Pleiotropic Effect of Flavonoids on NAD $(+)$ Levels in Endothelial Cells Exposed to High Glucose. Oxid Med Cell Longev, 2015: 894597.

[83] Lopez-Lopez JG, Moral-Sanz J, Frazziano G, GomezVillalobos MJ, Flores-Hernandez J, Monjaraz E, et al. (2008). Diabetes induces pulmonary artery endothelial dysfunction by NADPH oxidase induction. Am J Physiol Lung Cell Mol Physiol, 295 (5): L727-732.

[84] Gumieniczek A, Hopkala H, Wojtowicz Z, Wysocka $M$ (2002). Changes in antioxidant status of lung tissue in experimental diabetes in rabbits. Clinical Biochemistry, 35 (2): 147-149.

[85] Lei SQ, Li YA, Liu HM, Yu H, Wang H, Xia ZY (2012). Effects of N-Acetylcysteine on Nicotinamide Dinucleotide Phosphate Oxidase Activation and Antioxidant Status in Heart, Lung, Liver and Kidney in Streptozotocin-Induced Diabetic Rats. Yonsei Medical Journal, 53 (2): 294-303.

[86] Coughlan MT, Thorburn DR, Penfold SA, Laskowski A, Harcourt BE, Sourris KC, et al. (2009). RAGEinduced Cytosolic ROS Promote Mitochondrial Superoxide Generation in Diabetes. Journal of the American Society of Nephrology, 20 (4): 742-752.

[87] Schmidt AM, Hori O, Cao R, Yan SD, Brett J, Wautier 
JL, et al. (1996). RAGE - A novel cellular receptor for advanced glycation end products. Diabetes, 45: S77S80.

[88] Zhong P, Wu L, Qian Y, Fang Q, Liang D, Wang J, et al. (2015). Blockage of ROS and NF-kappaBmediated inflammation by a new chalcone L6H9 protects cardiomyocytes from hyperglycemia-induced injuries. Biochim Biophys Acta, 1852 (7): 1230-1241.

[89] Sun CK, Lee FY, Sheu JJ, Yuen CM, Chua S, Chung SY, et al. (2009). Early combined treatment with cilostazol and bone marrow-derived endothelial progenitor cells markedly attenuates pulmonary arterial hypertension in rats. J Pharmacol Exp Ther, 330 (3): 718-726.

[90] Yagi O, Aoshiba K, Nagai A (2006). Activation of nuclear factor-kappaB in airway epithelial cells in patients with chronic obstructive pulmonary disease. Respiration, 73 (5): 610-616.

[91] Zhang F, Yang F, Zhao H, An Y (2015). Curcumin alleviates lung injury in diabetic rats by inhibiting NFkappaB pathway. Clin Exp Pharmacol Physiol.

[92] Martins JO, Ferracini M, Anger DB, Martins DO, Ribeiro LF, Jr., Sannomiya P, et al. (2010). Signaling pathways and mediators in LPS-induced lung inflammation in diabetic rats: role of insulin. Shock, 33 (1): 76-82.

[93] Bey EA, Xu B, Bhattacharjee A, Oldfield CM, Zhao $\mathrm{X}$, Li Q, et al. (2004). Protein kinase $\mathrm{C}$ delta is required for $\mathrm{p} 47$ phox phosphorylation and translocation in activated human monocytes. J Immunol, 173 (9): 5730-5738.

[94] Wu J, Yan LJ (2015). Streptozotocin-induced type 1 diabetes in rodents as a model for studying mitochondrial mechanisms of diabetic beta cell glucotoxicity. Diabetes Metab Syndr Obes, 8: 181-188. [95] Jin Z, Wu J, Yan LJ (2016). Chemical Conditioning as an Approach to Ischemic Stroke Tolerance: Mitochondria as the Target. Int J Mol Sci, 17 (3).

[96] Onyango IG, Dennis J, Khan SM (2016). Mitochondrial Dysfunction in Alzheimer's Disease and the Rationale for Bioenergetics Based Therapies. Aging Dis, 7 (2): 201-214.

[97] Bonomini F, Rodella LF, Rezzani R (2015). Metabolic syndrome, aging and involvement of oxidative stress. Aging Dis, 6 (2): 109-120.

[98] Victor VM, Rocha M, Herance R, Hernandez-Mijares A (2011). Oxidative stress and mitochondrial dysfunction in type 2 diabetes. Curr Pharm Des, 17 (36): 3947-3958.
[99] Fernyhough P, Jonathan M (2014). Mechanisms of disease: Mitochondrial dysfunction in sensory neuropathy and other complications in diabetes. Handb Clin Neurol, 126: 353-377.

[100] Blake R, Trounce IA (2014). Mitochondrial dysfunction and complications associated with diabetes. Biochim Biophys Acta, 1840 (4): 1404-1412.

[101] Bhatt MP, Lim YC, Kim YM, Ha KS (2013). Cpeptide activates AMPKalpha and prevents ROSmediated mitochondrial fission and endothelial apoptosis in diabetes. Diabetes, 62 (11): 3851-3862.

[102] Towler DA (2013). Mitochondrial ROS deficiency and diabetic complications: AMP[K]-lifying the adaptation to hyperglycemia. J Clin Invest, 123 (11): 4573-4576.

[103] Anthonsen S, Larsen J, Pedersen PL, Dalgaard LT, Kvetny J (2013). Basal and T(3)-induced ROS production in lymphocyte mitochondria is increased in type 2 diabetic patients. Horm Metab Res, 45 (4): 261 266.

[104] Lindblom R, Higgins G, Coughlan M, de Haan JB (2015). Targeting Mitochondria and Reactive Oxygen Species-Driven Pathogenesis in Diabetic Nephropathy. Rev Diabet Stud, 12 (1-2): 134-156.

[105] Yu T, Sheu SS, Robotham JL, Yoon Y (2008). Mitochondrial fission mediates high glucose-induced cell death through elevated production of reactive oxygen species. Cardiovasc Res, 79 (2): 341-351.

[106] Yan LJ, Rajasekaran NS, Sathyanarayanan S, Benjamin IJ (2005). Mouse HSF1 disruption perturbs redox state and increases mitochondrial oxidative stress in kidney. Antioxid Redox Signal, 7 (3-4): 465471.

[107] Skulachev VP (1998). Cytochrome c in the apoptotic and antioxidant cascades. FEBS Lett, 423 (3): 275-280.

[108] Yan LJ, Christians ES, Liu L, Xiao X, Sohal RS, Benjamin IJ (2002). Mouse heat shock transcription factor 1 deficiency alters cardiac redox homeostasis and increases mitochondrial oxidative damage. EMBO J, 21 (19): 5164-5172.

[109] Ni R, Cao T, Xiong S, Ma J, Fan GC, Lacefield JC, et al. (2016). Therapeutic inhibition of mitochondrial reactive oxygen species with mito-TEMPO reduces diabetic cardiomyopathy. Free Radic Biol Med, 90: 12-23.

[110] Sivitz WI, Yorek MA (2010). Mitochondrial dysfunction in diabetes: from molecular mechanisms to functional significance and therapeutic opportunities. Antioxid Redox Signal, 12 (4): 537-577. 